\title{
Growth of Nanotubes for Probe Microscopy Tips
}

\section{Citation}

Hafner, Jason H., Chin Li Cheung, and Charles M. Lieber. 1999. Growth of nanotubes for probe microscopy tips. Nature 398: 761-762.

\section{Published Version}

http://dx.doi.org/10.1038/19658

\section{Permanent link}

http://nrs.harvard.edu/urn-3:HUL.InstRepos:2710478

\section{Terms of Use}

This article was downloaded from Harvard University's DASH repository, and is made available under the terms and conditions applicable to Other Posted Material, as set forth at http:// nrs.harvard.edu/urn-3:HUL.InstRepos:dash.current.terms-of-use\#LAA

\section{Share Your Story}

The Harvard community has made this article openly available.

Please share how this access benefits you. Submit a story.

Accessibility 


\title{
Growth of nanotubes for probe microscopy tips
}

\author{
Jason H. Hafner, Chin Li Cheung, and Charles M. Lieber \\ Department of Chemistry and Chemical Biology, Harvard University, 12 Oxford Street, Cambridge, Massachusetts 02138, USA \\ Correspondence: C. M. Lieber, email: $\underline{\mathrm{cml} @ \text { cmliris.harvard.edu }}$
}

Carbon nanotubes, which have intrinsically small diameters and high aspect ratios and which buckle reversibly, make potentially ideal structures for use as tips in scanning probe microscopies, such as atomic force microscopy (AFM) $1,2,3,4$. However, the present method of mechanically attaching nanotube bundles for tip fabrication is time consuming and selects against the smallest nanotubes, limiting the quality of tips. We have developed a technique for growing individual carbon nanotube probe tips directly, with control over the orientation, by chemical vapour deposition (CVD) from the ends of silicon tips. Tips grown in this way may become widely used in high-resolution probe microscopy imaging.

Our approach to growing individual nanotube probes involves flattening a conventional silicon (Si) tip at its apex by contact AFM imaging and anodizing it in hydrogen fluoride ${ }^{5}$ to create nanopores of 50-100 $\mathrm{nm}$ diameter along the tip axis. Iron catalyst is electrodeposited into the pores from $\mathrm{FeSO}_{4}$ solution $^{6}$, and nanotubes are grown by CVD with ethylene and hydrogen at $750{ }^{\circ} \mathrm{C}$. The orientated pore structure was chosen for the catalyst support in order to control the direction of growth ${ }^{7}$ and enable the reproducible production of nanotube tips for imaging.

CVD nanotube tips are formed reproducibly after a reaction lasting $10 \mathrm{~min}$ (Figure 1). They are usually too long to be used as tips, and are shortened by an in situ AFM technique ${ }^{1},{ }^{2}$. A typical field-emission scanning electron microscopy (FESEM) image of a nanotube tip after it was shortened and used for AFM imaging (Figure 1a) shows a well-defined tube 480 $\mathrm{nm}$ long protruding from the Si tip apex. Nanotube tips produced under these conditions and viewed by FE-SEM have an average diameter of $10 \pm 5 \mathrm{~nm}$. Further characterization of these tips by transmission electron microscopy show that they are multi-walled nanotubes (MWNTs) with well-ordered graphene walls (Figure 1b).

AFM measurements of the cantilever oscillation amplitude versus the position above a substrate (Figure 1c) show that these individual nanotubes buckle elastically, as observed previously for mechanically attached, arc-grown MWNTs ${ }^{1}$. Buckling curves can be repeated many times for a given tip, demonstrating that both the nanotube and its attachment to the Si tip are robust, and can be used to verify in situ that the nanotube tip is used for imaging.

The imaging performance of CVD nanotube probes has been characterized using gold nanoparticle standards ${ }^{8}$ and immunoglobulin M. Gold nanoparticles with mean diameters of 2 and $5 \mathrm{~nm}$ were imaged on mica, and the image widths were used with a two-sphere model to estimate the tip resolution. The results show that we can routinely obtain very high-resolution tips with end radii of 3-6 nm. This is an improvement on our previous MWNT tips ${ }^{2}$, our single-walled nanotube ${ }^{4}$ (SWNT) bundle tips, and commercial $\mathrm{Si}$ and $\mathrm{Si}_{3} \mathrm{~N}_{4}$ tips, whose radii are generally greater than 5-10 nm. Our tips are also very robust and do not readily contaminate (in contrast to the sharpest $\mathrm{Si}$ and $\mathrm{Si}_{3} \mathrm{~N}_{4}$ ones). They can be used several times and, when a tip ultimately fails, the carbon is removed by oxidation (at $500{ }^{\circ} \mathrm{C}$ for $20 \mathrm{~min}$ ) and a new tip is grown by CVD. Tips have been through this cycle 20 times with no loss of yield or resolution.

These single nanotube tips may also be used for imaging biological macromolecules. For example, intermittent contact AFM images of IgM (Figure 2) show excellent resolution. Routine images show the pentameric structure, including five external pairs of antigen-binding fragments and five internal crystallizable fragment domains ${ }^{9}$. Images occasionally exhibit a loop structure connecting two of the five domains that might 


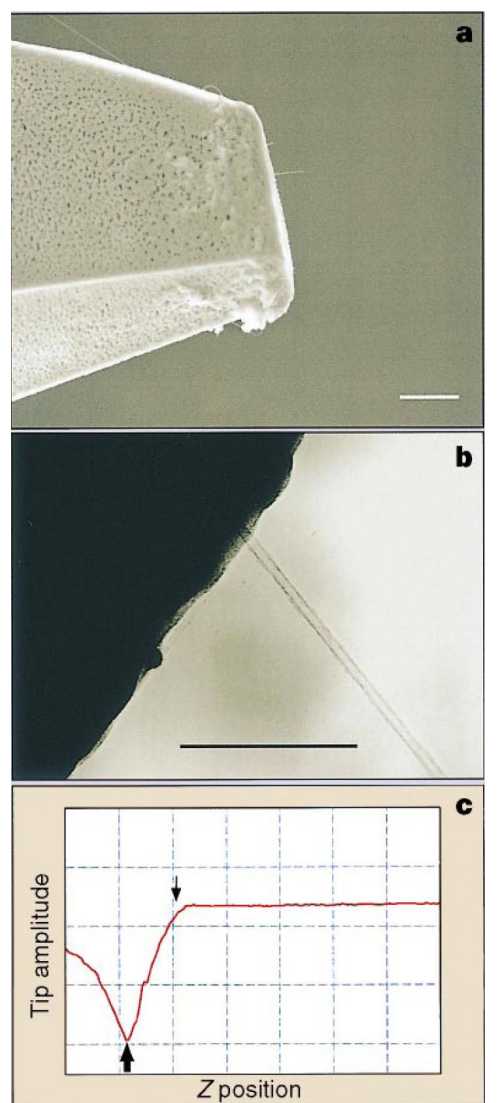

Figure 1. Characterization of CVD nanotube tips. a, FE-SEM image of a CVD nanotube tip that has been shortened for imaging. Nanotubes were grown from a uniform pore structure consisting of pores about 60 $\mathrm{nm}$ in diameter, with 150 pores per $\mu \mathrm{m}^{2}$. Scale bar, $1 \mu \mathrm{m}$. b, Transmission electron microscope (TEM) image of a CVD nanotube tip. The entire AFM cantilever/tip assembly with nanotube tip was mounted on a custom TEM holder for imaging. Scale bar, $100 \mathrm{~nm}$. c, Tip oscillation amplitude (grid marks $5 \mathrm{~nm}$ apart) as a function of height above the sample ( $Z$ position; grid marks $2 \mathrm{~nm}$ apart) recorded in force calibration mode with a Nanoscope III (Digital Instruments). The right of the plot corresponds to free oscillation of the tip above the surface. As the tip approaches and begins to tap the surface (thin arrow), the amplitude decreases to zero. The oscillation amplitude increases again after the nanotube buckles (thick arrow). CVD nanotubes were grown in a tube furnace. Tips (with catalyst) were heated by $15^{\circ} \mathrm{C}$ per min to 750 ${ }^{\circ} \mathrm{C}$ in a flow of 950 STP $\mathrm{cm}^{3} \mathrm{~min}^{-1}$ argon and 40 STP $\mathrm{cm}^{3} \mathrm{~min}^{-1}$ hydrogen. At $750{ }^{\circ} \mathrm{C}, 10 \mathrm{STP} \mathrm{cm} \mathrm{min}^{-1}$ ethylene was added for $10 \mathrm{~min}$, and the furnace was cooled at $15^{\circ} \mathrm{C}$ per min in $500 \mathrm{STP} \mathrm{cm}^{3} \mathrm{~min}^{-1}$ argon.

correspond to the joining loop 9 . Higher-resolution AFM images have been reported using commercial tips ${ }^{10},{ }^{11}$, but only of densely packed arrays of proteins. When individual molecules have been imaged with these same tips, the resolution is lower ${ }^{11}$.

Individual CVD nanotube tips routinely show higher-resolution images of isolated protein molecules than our previous results with MWNT and SWNT bundle tips (consistent with measurements on gold nanoclusters) and room-temperature AFM data with commercial tips ${ }^{12}$, and are comparable to the high-resolution data obtained at low temperatures by cryo$\mathrm{AFM}^{13}$. Our results reflect the small radii, cylindrical shape and low adhesion forces (typically less than $30 \mathrm{pN}$ ) of individual MWNT tips.

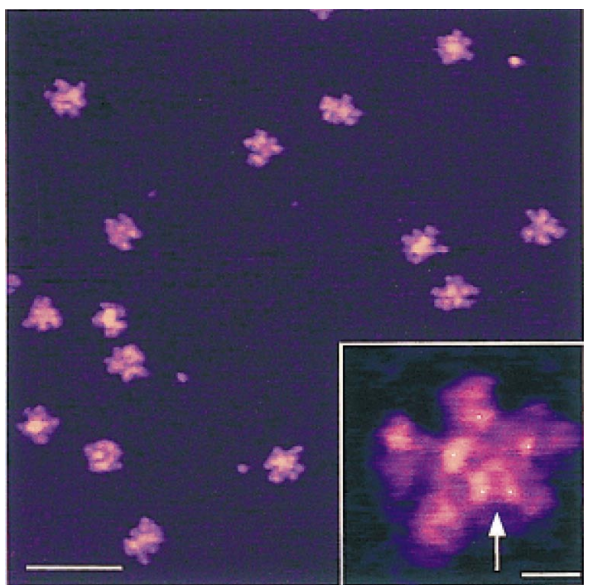

Figure 2. Imaging IgM macromolecules with a CVD nanotube tip at high resolution. Apparent structural differences in individual IgMs are due to absorption in different orientations. Molecular height ranges from 2.5 to $3.5 \mathrm{~nm}$. Scale bar, $100 \mathrm{~nm}$. Inset, high-resolution image of IgM. Small white dots, crystallizable Fc fragments; white arrow, possible position of the joining loop. Scale bar, $10 \mathrm{~nm}$. Images were recorded in tapping mode in air with CVD nanotube tips grown on forcemodulation-etched Si probes. Samples were prepared from mouse $\operatorname{lgM}\left(>95 \%\right.$, Sigma) by diluting to $2 \mathrm{mg} \mathrm{ml}^{-1}$ in $0.05 \mathrm{M}$ phosphate-buffered saline solution, $\mathrm{pH} 7.0 ; 25 \mu \mathrm{l}$ of the solution was dropped onto freshly cleaved mica, allowed to stand for $1 \mathrm{~min}$, rinsed with water and dried with nitrogen.

The high resolution of individual MWNT tips means that they could be used for imaging nanostructures and functional mapping when the ends are modified ${ }^{3}$. This CVD method also could be implemented on a large scale, making nanotube tips widely accessible. The resolution may be further improved by preparing smaller-diameter SWNT tips ${ }^{14},{ }^{15}$, leading to their use in many areas of biology and chemistry.

\section{References}

1. Dai, H. , Hafner, J. H. , Rinzler, A. G. , Colbert, D. T. \& Smalley, R. E. Nature 384, 147-150 (1996).

2. Wong, S. S., Harper, J. D., Lansbury, P. T. \& Lieber, C. M. J. Am Chem. Soc. 120, 603-604 (1998).

3. Wong, S. S. , Joselevich, E. , Woolley, A. T. , Cheung, C. L. \& Lieber, C. M. Nature 394, 52-55 (1998).

4. Wong, S. S. et al. Appl. Phys. Lett. 73, 3465-3467 (1998).

5. Lehmann, V. Thin Solid Films 255, 1-4 (1995).

6. Ronkel, F. , Schultze, J. W. \& Arens-Fischeer, R. Thin Solid Films 276, 40-43 (1996).

7. Li, W. Z. et al. Science 274, 1701-1703 (1996).

8. Vesenka, J., Manne, S., Giberson, R., Marsh, T. \& Henderson, E. Biophys. J. 65, 992-997 (1993).

9. Perkins, S. J., Nealis, A. S., Sutton, B. J. \& Feinstein, A. J. Mol. Biol. 221, 1345-1366 (1991).

10. Shao, Z. , Mou, J., Czajkowsky, D. M., Yang, J. \& Yuan, J.-Y. Adv. Phys. 45, 1-86 (1996

11. Muller, D. , Amrein, M. \& Engel, A. J. Struct. Biol. 119, 172-188 (1997).

12. Fritz, J. , Anselmetti, D., Jarchow, J. \& Fernandez-Buusquets, X. J. Struct. Biol. 119, 165-171 (1997).

13. Zhang, Y., Sheng, S. \& Shao, Z. Biophys. J. 71, 2168-2176 (1996).

14. Kong, J., Soh, H. T. , Cassell, A. M., Quate, C. F. \& Dai, H. Nature 395, 878-881 (1998).

15. Hafner, J. H. et al. Chem. Phys. Lett. 296, 195-202 (1998). 